\title{
A RESPONSABILIDADE dOS PODERES PÚBlicos NA POLÍTICA DE SAÚdE: UM BALANÇO DA ATUAÇÃO DOS PODERES
}

\author{
Congresso Brasileiro Online de Direito, 1 ạ edição, de 11/10/2021 a 13/10/2021
}

ISBN dos Anais: 978-65-89908-73-9

MEDINA; Lízia Coelho ${ }^{1}$, SANTOS; Claudio Roberto Santos ${ }^{2}$, NUNES; Flávio Fllgueiras ${ }^{3}$, FELIPE; Bruno Farage da Costa 4, BASTOS; Danuza da Silva Crespo ${ }^{5}$

\section{RESUMO}

A emergência de demandas sociais resulta da tensão entre democracia e capitalismo. As políticas de saúde desempenham um papel estruturante no Estado de Bem-estar brasileiro. A Constituição de 1988 inaugurou uma nova era em termos de políticas de saúde. O Brasil é inserido no rol dos países que propugnam a universalização da saúde ao contemplá-la como direito de todos e dever do Estado. Para dar materialidade políticoinstitucional à política social de saúde, a Constituição instituiu o Sistema Único de Saúde (SUS). Considerada um dos pilares dos sistemas ocidentais de proteção social, a saúde pública articula-se, em geral, a outras políticas sociais. Ao se estudar políticas públicas faz-se necessário recorrer às conexões entre Estado, política, economia e sociedade. A saúde pública é prestada de múltiplas formas, cujas variáveis decorrem do contexto político-econômico. Inúmeras responsabilidades dos Poderes Públicos transcendem a área da saúde e implicam conexões com outros setores governamentais. Por exemplo, o SUS também deve atuar mediante a participação na formulação da política e na execução de ações de saneamento básico; formular política de medicamentos, equipamentos, vacinas, imunobiológicos e outros insumos de interesse para a saúde e participar da sua produção, fiscalização. As múltiplas responsabilidades dos Poderes dos Poderes Públicos na política de saúde geram implicações para a compreensão do SUS como política de Estado, envolvendo ações articuladas pelas três instâncias federativas. Diante desse contexto, o estudo objetiva identificar o papel do Estado na saúde a partir de 1990, considerando a atuação dos Poderes. Para o desenvolvimento deste trabalho, a metodologia utilizada foi a revisão de literatura e a análise de dados estatísticos. Como resultado esperado da pesquisa, destacam-se as seguintes conclusões: 1) A responsabilidade pela saúde pública não é apenas setorial; 2) As políticas econômicas e sociais devem estar integradas com as políticas de saúde; 3) A atuação coordenada das três esferas de governo deve articular-se com os demais Poderes, o Ministério Público e a sociedade.

PALAVRAS-ChAVE: Direito à Saúde, Poder Executivo, Poder Legislativo, Poder Judiciário, Política de saúde 